\title{
Congenital adducted thumb: Role of the index transposition flap
}

Hugh G Thomson MD MS FRCSC FACS, Douglas Grace MD

The Hospital for Sick Children, Toronto, Ontario

HG Thomson, D Grace. Congenital adducted thumb: Role of the index transposition flap. Can J Plast Surg 1996;4(2):105-108. This study examines the results of a large length:width ratio transposition flap used for the correction of the congenitally adducted thumb. The flap is elevated from the radial side of the index finger and transposed into the palm parallel to the thenar crease. Long term analysis of flap results included the disappearance of a transverse palmar white line; length:width ratios; angle of abduction of thumb; sensation of flap; and functional assessment of thumb and index finger. There were 49 adducted thumbs operated on and 26 flaps were clinically examined with an average length:width ratio of $3.5: 1$, with some flaps having ratios of up to $6: 1$. All adducted thumbs were adequately released with no complications encountered.

Key Words: Congenital adducted thumb, Index transposition flap, Length:width ratio

Adduction congénitale du pouce : rôle du lambeau de transposition de l’index

RÉSUMÉ : Cette étude examine les résultats d'un lambeau de transposition de fort ratio longueur:largeur utilisé pour la correction d'une adduction congénitale du pouce. Le lambeau a son origine du côté radial de l'index et est transposé vers la paume, parallèlement au pli thénar. L'analyse à long terme des résultats du lambeau portait sur la disparition de la ligne blanche palmaire transversale, sur les ratios longueur:largeur, sur l'angle de l'adduction du pouce, sur la sensibilité du lambeau et sur l'évaluation fonctionnelle du pouce et de l'index. Quarante-neuf adductions de pouce ont été effectuées et 26 lambeaux ont été examinés. Sur le plan clinique, ils présentaient un ratio moyen longueur:largeur de 3,5:1, certains lambeaux présentant des ratios pouvant atteindre 6:1. Toutes les adductions de pouces ont été adéquatement libérées sans complications.

Congenital adduction of the thumb, if left uncorrected, can be a significant functional handicap. The adequacy of the first web is determined by the interrelationship of three anatomical structures: the skin, muscles within the web area, and trapeziometacarpal joint. The simple congenital adduction contracture of the thumb is mainly one of inadequate skin coverage and in most patients represents a degree of syndactyly of the first two radial rays. In more severe cases it may also involve the muscles which occupy the web (1). 
The adducted thumb may present as an isolated anomaly or as part of a syndrome such as Poland's, Turner's, Möebius', Freeman-Sheldon, and the congenital clasped thumb as described by Weckesser et al (2). Also, it occurs to some degree in all patients with thumb duplication.

In simple cases, deepening of the first web by such conventional methods as the four flap Z-plasty and V-Y advancement may result in an adequate release. In more severely adducted thumbs many techniques, such as abdominal flaps, local rotational flaps with a full thickness skin graft or a simple diamond shaped skin graft, have all been suggested with varying aesthetic and functional results (1,3-9) (Figure 1). To abduct the thumb fully, in addition to skin lengthening, the adductor pollicis may have to be released from the third metacarpal, and the first dorsal interosseous released from the first metacarpal (10). In this study an additional technique of an index transposition flap into the palm, as originally reported by Spinner (4) in 1969, has been modified and is suggested because of its potential aesthetic and functional advantages for the correction of this adduction deformity.

\section{SURGICAL TECHNIQUE}

A strong indicator of the adducted thumb phenomenon is the presence of the palmar white line when passively separating the thumb and little finger (Figure 1). If this condition is present in infancy, prevention of further soft tissue contraction or even correction should be attempted by abduction-extension splinting for at least three months along with parental stretching of the first web space. In their report, Weckessor et al suggest prolonged plaster splinting (2). They advocate a long period of immobilization, up to six months, and report long term maintenance of the correction in patients with a good response to splinting (11). The investigators agree and believe surgery is indicated only if the palmar white line persists after a prolonged and monitored splinting program of six months to a year. The splint is worn for $23 \mathrm{~h}$ a day for the first two months and at night thereafter.

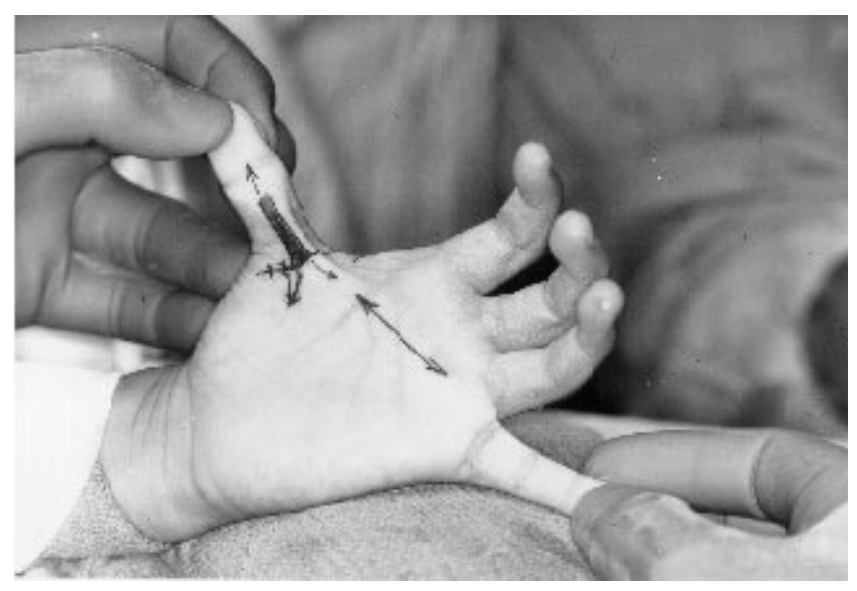

Figure 1) White linear contracture across palm from thumb to little finger. Area to be lengthened at right angles parallel to thenar crease at level of curved arrow heads 
If surgery is ultimately necessary due to partial or complete splint failure, the adducted thumb is released by designed incisions which transpose skin from the radial aspect of the proximal phalanx of the index finger to the created defect in the web space and palm. Prerequisites for adequate release of the adducted thumb include elimination of the white line and sufficient release proximally, on the palmar and dorsal aspects of the thumb-index web area (Figure 2). Release of the adductor pollicis, first dorsal interosseous, deep head of the flexor pollicis brevis, and capsular release of the carpometacarpal joint are rarely necessary.

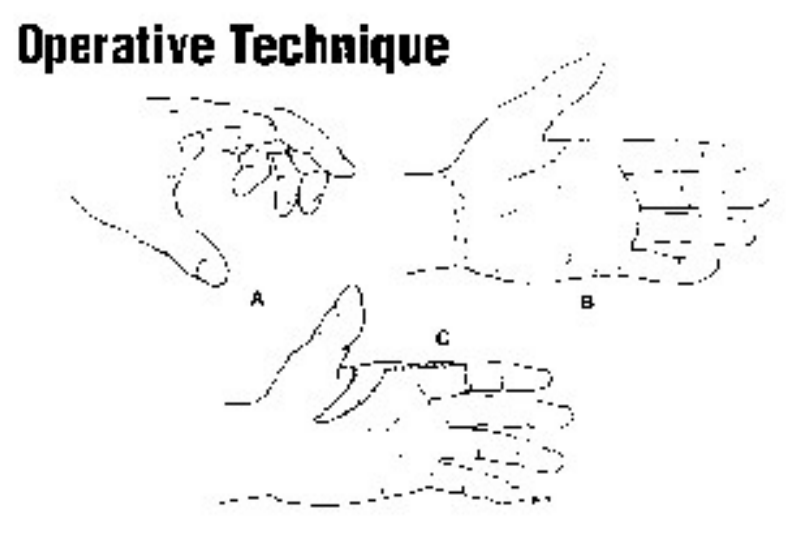

Figure 2) Operative technique. (A) Outline of flap dorsal to mid-lateral creases and extending to proximal interphalangeal crease. (B) Palmar incision parallel to thenar crease. (C) Donor site closed directly and flap in position

A long isosceles triangular flap is designed, keeping dorsal to the radial midlateral line of the index finger. The flap is fashioned as wide as possible and still permits direct closure of the index donor site. The long donor flap usually extends to the proximal interphalangeal (PIP) joint of the index with the releasing incision continuing across the contracted web space and curving radial and almost parallel to the thenar crease.

The underlying structures are easily visualized and the contracted fascia between the first and second metacarpals is released. The donor site is closed directly, although there may be exceptions if an overzealous flap has been designed. A full thickness skin graft from the bikini area of the abdomen-groin is used if additional abduction is necessary or the overzealous index donor site is to be closed. This can be in the form of a single graft on the thumb side and/or additionally on the index side (Figure 3). 


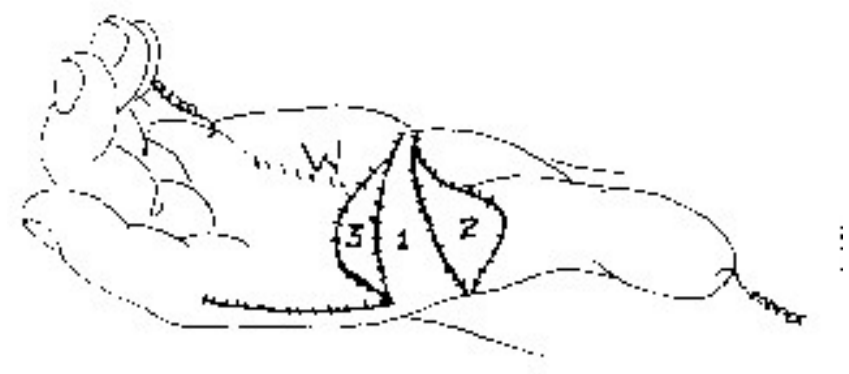

Figure 3) $W$-broken white line; \#1 is flap in place; \#2 and \#3 could be free full thickness skin grafts used singly or together if necessary

A protective thermoplast splint is fabricated to keep the thumb in maximum abducted position at the end of the procedure. After the primary dressing change, a new splint is worn at night for three months. Rarely, $\mathrm{K}$ wires are used to aid in maintaining initial abduction.

\section{MATERIALS AND METHODS}

On the senior author's service between 1985 and 1994 at The Hospital for Sick Children, 34 patients with adducted thumbs received an index transposition flap.

Fifteen patients had bilateral adducted thumbs and eight received transposition flaps to both hands for a total of 49 adducted thumbs in the study, with 42 thumbs having an index transposition flap (Figure 4). The average age at operation was five years of age with patients ranging from three months to 18 years old. There were 24 males and 10 females. Patients with adducted thumbs presented with single and multiple anomalies.

All patient charts were reviewed and 22 patients representing 26 thumb flaps were directly examined for this retrospective study. The average time of follow-up was five years postoperatively with times ranging from two weeks to nine years.

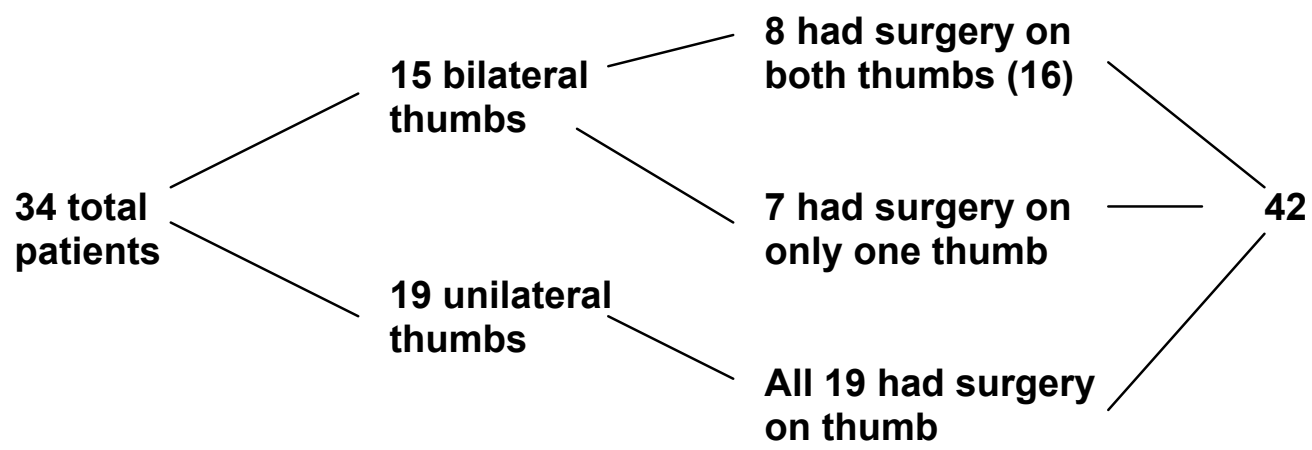

Figure 4) Laterality of adducted thumb 
Several parameters were investigated to assess the outcome of the procedure: elimination of the palmar white line; the flap dimensions were measured with a micrometer; the angle of abduction from the index PIP joint to the thumb interphalangeal joint was determined using a goniometer; the index finger and palmar flap were assessed for both function and sensation using two-point discrimination testing as described by Mackinnon and Dellon (13) along with starch and iodine testing; and flap texture and pigmentation were noted.

\section{RESULTS}

In this study the white line was eliminated completely in 21 hands and reduced to being only very slight in the remaining five hands. The mean flap length:width ratio was $3.5: 1$. The length in this study ranged from $26 \mathrm{~mm}$ to $48 \mathrm{~mm}$. The flap widths ranged from $6 \mathrm{~mm}$ to $16 \mathrm{~mm}$ with the mean width being $12 \mathrm{~mm}$. The mean length:width ratio is larger than those ordinarily recommended (4). There were no obvious flap complications and in more recent years the ratios became generally larger, even up to 6:1 (Figure 5).

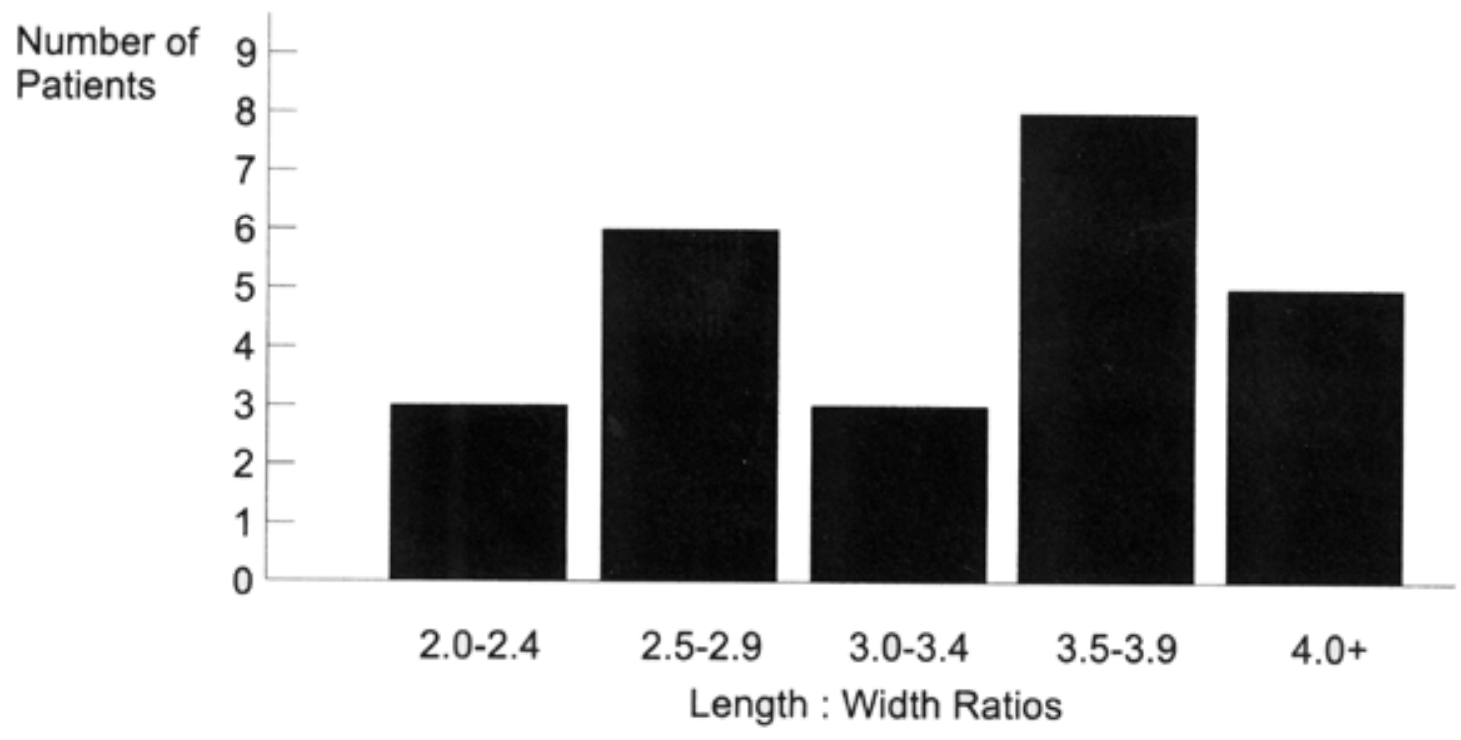

Figure 5) Length:width ratios

Some flaps showed mature scarring at the distal tip insertion site of the flap of 1 to $2 \mathrm{~mm}$ which was probably caused by either flap retraction or micronecrosis.

An additional full thickness skin graft was used if the flap was inadequate to close the created thenar defect. One patient also had a skin graft on the index finger donor site to aid in adequate closure due to inappropriate flap design (Table 1). 
TABLE 1: Number of full thickness skin grafts

$\begin{array}{ccc} & \text { In palm } & \text { On index finger } \\ \text { One skin graft } & \text { Two skin grafts } & \text { One skin graft } \\ 6 & 4 & 1\end{array}$

Goniometer measurement of the abduction angle was completed (Figure 6). In patients with unilateral adducted thumbs the average active angle of abduction of the released thumb was $72.7^{\circ}$ which was $93 \%$ of their opposite, normal thumb values. In the released thumbs the passive angle of abduction was $95.2^{\circ}$ which was $96 \%$ of their normal thumb values. In bilateral patients the average angle of active abduction was $62.6^{\circ}$ which was $69 \%$ of values of other patients used as controls, without thumb adduction deformities. The average passive angle of abduction was $74.5^{\circ}$ which was $72 \%$ of comparative, normal thumb values.

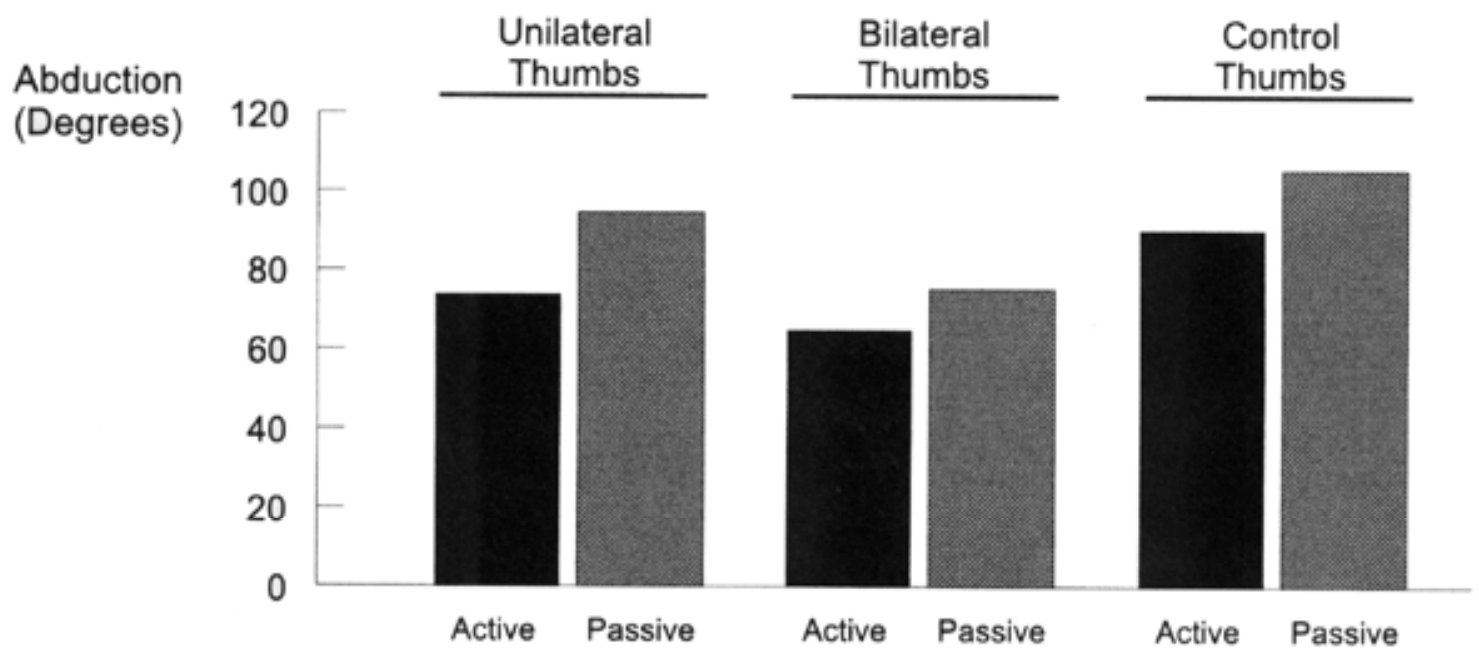

Figure 6) Angle of abduction both active and passive

Two-point discrimination has been demonstrated to be a valid measurement of functional sensibility of the hand (13), and along with starch and iodine testing was used to assess regional sensation of the transposition flap and donor site. The patients tested had two-point discrimination of between $2 \mathrm{~mm}$ and $3 \mathrm{~mm}$ on the touchpad of the index finger. Also, the starch and iodine sweat test on the flap was compared to an adjacent finger touch pad. All flaps had a positive starch and iodine test at an average of $26.1 \mathrm{~s}$ compared with the control results of $25.2 \mathrm{~s}$. Both the index finger and thumb appeared to have no decrease in either function or sensation postoperatively as tested by two-point and starch and iodine compared to controls (Table 2). 
TABLE 2: Sensation assessment, comparing controls and surgical patients using twopoint discrimination and starch and iodine

$\begin{array}{ll}\text { A) Two-point discrimination }(\mathrm{n}=13) & \\ \text { Patients with surgery } & \\ & 3 \mathrm{~mm}=6 \text { patients } \\ & 2 \mathrm{~mm}=7 \text { patients } \\ \text { Control patients } & 3 \mathrm{~mm}=9 \text { patients } \\ & \\ \text { B) Starch and iodine }(\mathrm{n}=26) & 25.2 \mathrm{~s} \\ \text { Adjacent finger control: } & 26.1 \mathrm{~s} \\ \text { Flap: } & \end{array}$

The flap texture in all patients was normal with no donor or recipient hypertrophy. However, skin graft hyperpigmentation did occur in six patients.

\section{DISCUSSION}

Lister stated that "nature abhors a vacuum, but a sturdy flap can tolerate one. Such a situation exists in skin defects of the first web space, for which a local transposition flap is an ideal solution" (6). From this study it is apparent the index finger transposition flap is adequate for release of the adducted thumb. With the addition of a skin graft in some patients the procedure is easy to complete. It is important to insert the flap in the appropriate axis. This procedure gives excellent access to the proximal phalanx of the thumb, the index finger and the metacarpophalangeal joints. An indicis proprius transfer was performed in five patients while performing the described transposition flap.

Of the 15 patients with bilateral adducted thumbs, seven thumbs responded well to splinting alone and did not require surgery. The length:width ratio of this random flap was greater than accepted but was shown to be viable in all cases with ratios of up to 6:1. It should be noted that this flap is well innervated by a branch of the superficial radial nerve as was also demonstrated by the positive starch and iodine tests (4). If a skin graft was required, the area to be grafted was a relatively hidden zone as opposed to the 'show' areas grafted in other adducted thumb release techniques. In raising the proximal portion of the flap excellent exposure for five indicis proprius tendon transfers was obtained. In all cases the donor site healed well without any complication such as hypertrophic scarring. There was no hyperpigmentation with the exception of the skin grafts. The function and sensation of the index finger was preserved in all donor fingers. The white line was eliminated in 21 hands and reduced to very slight in the remaining five hands of those patients examined.

The authors conclude the radial side of the index finger is an adequate and possibly preferred donor site for a regional transposition flap in the correction of the congenitally adducted thumb.

\section{REFERENCES}

1. Hentz VR. Congenital Anomalies of the Thumb. In: McCarthy JG, ed. Plastic Surgery, Vol 8: The Hand, Part 2. Philadelphia: WB Saunders Co, 1990:5116-9. 
2. Weckesser EC, Reed JR, Heiple KG. Congenital clasped thumb (congenital flexion adduction deformity of the thumb). J Bone Joint Surg [A] 1968;50:1417-28.

3. Kessler, I. Etiology and management of adduction contracture of the thumb. Bull Hosp for Joint Dis 1984;44:260-75.

4. Spinner M. Fashioned transpositional flap for soft tissue adduction contracture of the thumb. Plast Reconstr Surg 1969;44:345-8.

5. Sandzen SC. Dorsal pedicle flap for resurfacing a moderate thumb-index web contracture release. J Hand Surg 1982;7:21-4.

6. Lister G. The theory of the transpositional flap and its practical application in the hand. Clin Plast Surg 1981;8:115-27.

7. Dobyns JH, Wood VE, Bayne LG. Operative Hand Surgery. In: Green DP, ed. Congenital Hand Deformities, 2nd edn. New York: Churchill Livingston, 1988:389. 8. Wenner SM, Shalvoy RM. Two-stage correction of thumb adduction contracture in Freeman-Sheldon syndrome (craniocarpotarsal dysplasia). J Hand Surg 1989;14A:93740.

9. Caroli A, Zanasi S. First web-space reconstruction by Caroli's technique in congenital hand deformities with severe thumb ray adduction. Br Plast Surg 1989;42:653-9.

10. Wood VE, Bondi J. Treatment of the Windblown hand. J Hand Surg 1990;15A:431-8.

11. Ger E, Kupcha P. The management of trigger thumb in children.

J Hand Surg 1991;16A:944-7.

12. Littler JW. The prevention and the correction of adduction contracture of the thumb. Clin Orthop 1959;13:143-6.

13. Dellon A, Mackinnon S, Crosby P. Reliability of two-point discrimination measurements. J Hand Surg 1987;12A:693-6. 